\title{
Use of community spaces for sports and fitness - a case study of urban inhabitants in Shenzhen City, China
}

\author{
Xiangyang $\mathrm{Wu}^{1 *}$, Xinran $\mathrm{Qin}^{1}$, Huixing Zhou ${ }^{1}$ \\ 1 School of Architecture and Urban Planning, Shenzhen University \\ 1 Shenzhen Key Laboratory for Optimizing Design of Built Environment \\ *Corresponding Author, Email: xywu@szu.edu.cn
}

Received: Jan 5, 2018; Accepted: Feb 18, 2018

Key words: Fitness Sports, Recreation, Community Environment, Spatial Planning and Design, Questionnaire Survey

\begin{abstract}
Shenzhen is a Chinese city with a very fast-paced work and life environment. Because people there are often under high pressure, fitness and sports have great benefits for their health. In order to study the correlation between inhabitants' fitness and sports activities and the community environment, a questionnaire is designed based upon a review of the literature on fitness behavior and the community environment, and then 595 inhabitants of Shenzhen are surveyed in 2016. The survey involved the demographic information of the subjects, their fitness and sports activities, and the satisfaction of spaces for sports in urban communities. Through analysis of the questionnaire data by cross tabulation, patterns of how and where people like to do exercise have been found. Jogging and walking are the most popular individual activities, where the preferred places are neighborhood gardens, urban squares and parks. The most popular team sports are badminton, table tennis and tennis, where the preferred places are professional fitness clubs, urban squares or parks. Gender differences significantly determine the choice of sport. Males tend to cycle or run individually, and to play ball games as a team. Females prefer to do yoga or eight section brocade individually, and square dance as a team. The factors influencing the satisfaction of places for exercise are ordered as follows: accessibility, fresh air and a clean environment, and low cost. The main requests from locals for the improvement of the recreation environment are the supply of more kinds of sports facilities and fields and better maintenance and management of sports facilities. Some urban design strategies for enhancing the community's sports environment are recommended.
\end{abstract}

\section{INTRODUCTION}

Rapid economic development is placing a lot of pressure on people in Chinese urban areas. In June 2013, Ciming Health Checkup Management Group Company Limited (2013) released a white paper on the health of Chinese urban inhabitants in Beijing with The Association of Chinese Physicians, Chinese Hospital Association and the Beijing Institute of Health Assurance. The report revealed that 35-65 year olds suffer the most from chronic disease in China. Some unhealthy phenomena, such as obesity, 
dyslipidemia and fatty livers, and high blood pressure not only show a significant upward trend in this age group, but also similar issues in younger people. The survey highlighted that the prevalence of diabetes in first-tier cities in China was significantly higher than in second-tier cities. There is again significantly higher rates of these problems in second-tier cities than in third-tier cities. The survey also revealed that the number of inhabitants with osteoporosis and dental disease significantly increased between 2010 and 2012. Medical experts point out that the causes of urban inhabitants' chronic diseases are mainly related to urban environmental pollution, high work pressure and bad lifestyles. These health problems are more common and serious in Shenzhen, being a fast-paced metropolis. In 2014, according to a range of government statistics, high cholesterol in Shenzhen (18\%) was much higher than the national average (5.6\%) (Zheng, 2017), and the prevalence of gout in Shenzhen was $0.42 \%$, which was the three times more than the national average (Zhao \& Huang, 2016).

On March 16, 2016, the 12th National People's Congress (NPC) voted to approve a resolution on health issues in the 13th five-year plan for economic and social development. In the Chapter 60, "in order to promote the construction of [a] healthy China", the outline clearly proposes the implementation of the national fitness strategy. The government will develop sports, strengthen public sports fields and facilities, and open public sports facilities with little or no entry fees. In the action plan, it pointed out that the urban community would promote its 15 minute fitness circle, and public sports services should be fully provided to all inhabitants. The World Health Organization (WHO) issued proposals for achieving global health through sports which identified that for people over the age of 18 who do half an hour of moderately intense exercise more than twice per week, the possibility of suffering from cancer and other non-infective diseases will be significantly reduced. Children ( 5 to 17 years-old) can reduce the risk of certain diseases in the future if they undertake more than one hour per week of medium- or highintensity exercise (Sina Health Blog, 2011).

There are several studies on the correlation between fitness activities and the spatial environment in China. Ma et al. (2008) studied factors related to $\mathrm{Xi}$ 'an inhabitants' physical fitness by conducting a questionnaire survey on the inhabitants of six communities in the city. The results showed that the choices for fitness venues in Xi'an were relatively wide. The number of people who chose public health facilities (such as fitness squares) was up to $25.9 \%$ and those who chose a public open space accounted for $34.1 \%$. The number of people choosing sidewalks was the least at $10.3 \%$. It showed that the closest and most convenient fitness places were still preferable. Li (2013) discussed the correlation between sports behavior and the urban environment through case studies and data analysis. At the same time, she further compared the correlation between economic indicators and local sports facilities across different regions. Her results demonstrated that the level of economic development affected the development of the sports industry and expenditure for the construction of sports venues, and facilities in the exercise areas were lacking. Wei, Xia, and Wang (2014) studied the outdoor fitness areas of Chinese cities and gave a preliminary discussion on optimizing the fitness environment and improving health benefits by focusing on plant configuration. Weng et al. (2010) established a research model of the effect of the urban built environment on the health of inhabitants through the analysis of the impact of the urban built environment on the inhabitants' physical activity; his results illustrated that the urban built environment could cause a 
lack of physical activity and, in turn, a lack of physical activity would affect the inhabitants' health. The urban built environment was the main factor affecting physical activity due to multiple factors, such as the street grid layout, landscape architecture, fitness facilities and land use planning and environmental safety. There were three kinds of models, concept models, comprehensive models and data models, which could be used to study the influence of the urban built environment on physical activity and health. Liu, Liu, and Peng (2014) explained that by altering the city street design and municipal construction, countries in the European Union have changed the primary modes of travel for urban inhabitants; EU designs have reduced the use of motor vehicles and have taken other measures to increase opportunities for walking and cycling. This change has improved levels of physical activity by inhabitants. Research by Jiang et al. (2015) suggests that elaborate design of the urban green landscape could keep people healthy through different channels, including promoting physical activity, reducing mental issues and recovering from fatigue. Previous studies have shown that the green landscape can also supply ecological products and services, promoting social capital as well. Tsai, Chen, and Ning (2016) assesses the walking space and the living path of elders by out-door activity type, walking range time and walking environment to understand the activity conditions and types of elders in Taipei.

Besides Chinese research in this field, (Stevinson, Wiltshire, \& Hickson, 2015), through an interview survey of jogging groups of green roads in the UK, found that the participation rate of jogging was related to the pursuit of health and vitality, green road accessibility, community social cohesion, and outdoor natural setting, among other factors. Through the study on sports and fitness behavior of 1,803 inhabitants of Perth, Australia, Giles-Corti and Donovan (2002) found that locals' sports activities were affected by the social and physical environment, accessibility of sports facilities, and the social environment, while a good landscape promoted walking; inhabitants in Perth often used informal community facilities, such as streets, public open spaces, and beaches. Humpel, Owen, and Leslie (2002) studied 19 published papers on environmental factors affecting adults involved in sports activities; the conclusion was that accessibility, opportunities, and the aesthetic characteristics of the environment had significant impacts on their activities, and they proposed developing an environmental and ecological model to explain further. Jiao et al. (2015) aim to investigate the strengths and weaknesses of predictive models of outdoor recreation travel in UK.

Recent literature has revealed that fitness and sports correlate with many social, economic and physical environmental factors, however, some issues are rarely explored, such as how inhabitants do fitness activities. For example, there is little focus on companionship in these activities, regarding the choice to exercise individually or in teams, places for particular sports activities, or gender differences. This paper aims to fill this gap. Inspired from the above research, a study model can be made (Figure 1) from an environmental psychological perspective; this will be the theoretical model for this study on the correlation between urban inhabitants' community spaces and their fitness and sports. 


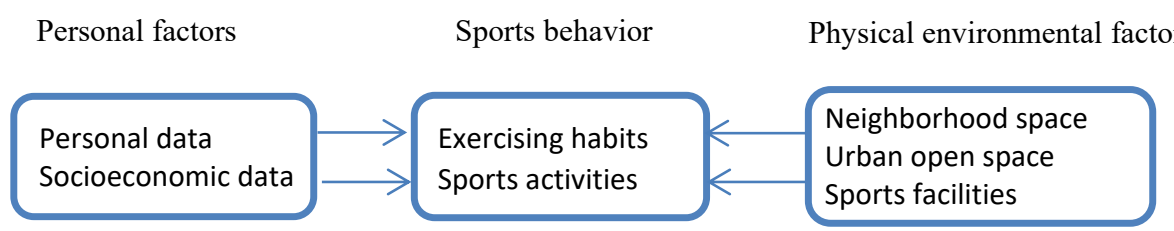

Figure 1. The model of the relation between the built environment and fitness and sports

\section{DESIGN OF THE QUESTIONNAIRE}

The questionnaire (Figure 2) is designed based on the environment and behavior model (Figure 1). The thirteen questions are mainly concerned with personal information, health status, exercise habits and modes, the choice of sports venues and satisfaction.

In November 2016, the students in Shenzhen University were invited to undertake a questionnaire survey on the fitness places in urban communities in Shenzhen. The respondents were all inhabitants of Shenzhen. The questionnaire was conducted via random sampling. The sampled sites were 15 communities, each over ten years old, in the urban area of Shenzhen. The research targeted respondents mainly near sports places, and they were interviewed at community centers.

There were 595 respondents and 525 samples were valid. The respondents consisted of $55.2 \%$ men and $44.8 \%$ women. The largest group was $19-30$ years old, at $42.3 \%$; the group of $30-50$ year olds followed with $23.4 \%$; the percentage of 50-60 year olds was $18.1 \%$; while the group aged between 7-18 years made up $10.5 \%$; , and the percentage of over 60 year olds was $5.7 \%$. By the end of 2015, according to the statistics of the national population census of Shenzhen, the total residential population of Shenzhen City was 11,378,900. The average age of the city's resident population was 32.53 years old. The male population was $6,100,100$ residents, accounting for $53.61 \%$, and the female population was $5,278,800$, accounting for $46.39 \%$. The respondents were from many different educational backgrounds: $49.7 \%$ with university degrees, $9 \%$ with higher education, $23 \%$ with a high school education, and $17.5 \%$ with a junior high school certificate or below. The subjects closely reflected the population characteristics of Shenzhen. The questionnaire data were analyzed with IBM's SPSS statistics software. 


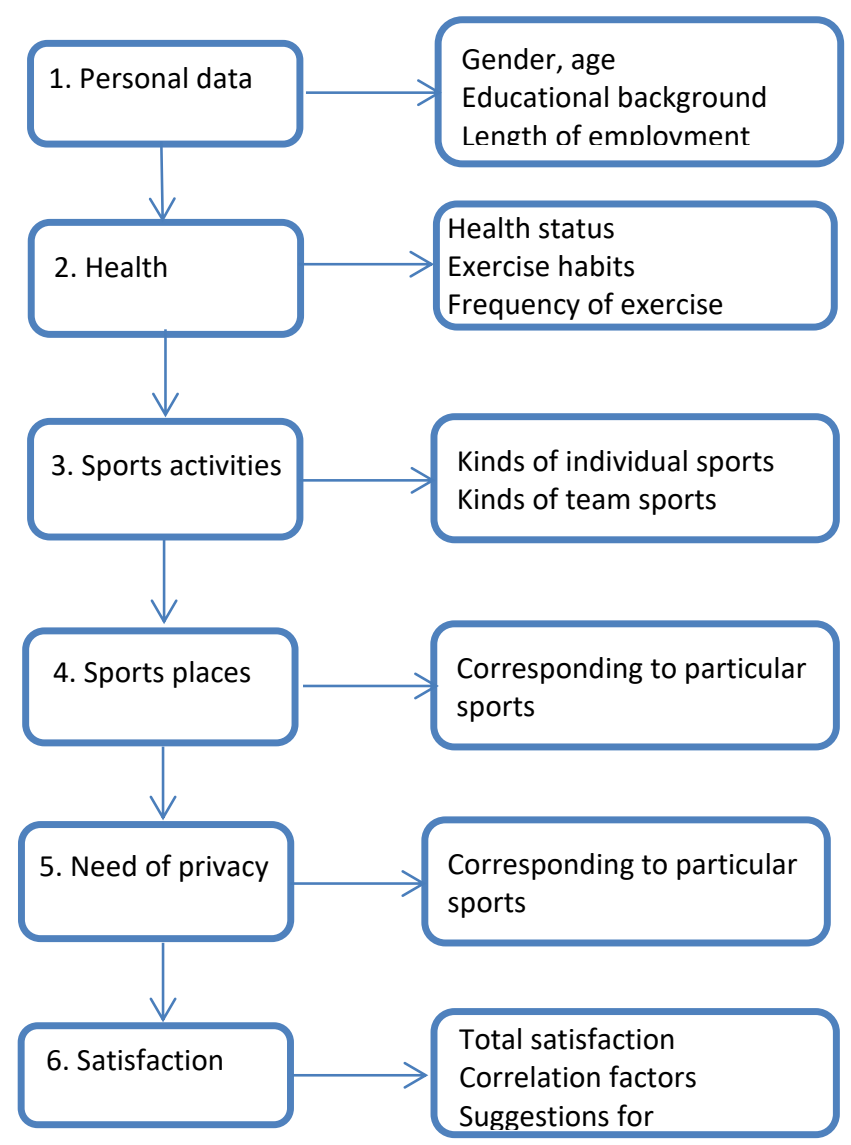

Figure 2. The Framework of the Questionnaire Design

\section{DATA ANALYSIS}

\subsection{The exercise habits of the respondents}

\subsubsection{Proportion of people with sports habits}

Among the respondents, $85.5 \%$ were in the habit of regular exercise. Males accounted for $48.4 \%$ and the females $36.6 \%$ of this. The group with no regular exercise accounted for about $14.5 \%$, with males at $6.9 \%$ and females composing $7.6 \%$ of this number. This shows that the majority of respondents in this survey make exercise a habit, and that men prefer sports more than women.

\subsubsection{Sports habits and educational background}

Data analysis indicates that $87.7 \%$ of those with tertiary education play sports and that $87.2 \%$ of those with graduate degrees or higher play sports. There is minimal difference between the two groups. $80 \%$ of those with senior high school education play sports, and of the remainder, with junior high school or lower education, $78.3 \%$ play sports. The group of people with tertiary education is significantly higher represented than other groups. 


\subsubsection{Exercise frequency and working time of the sports group}

According to cross analysis of exercise frequency and working time of the groups (Table 1), those who exercise 2-3 times a week accounted for $44.2 \%$ of the total population, and those who exercise daily made up $30 \%$ of the total population. The highest exercise frequency of a regular commuting group was 2-3 times per week, while those who were paid for their time while exercising tended to exercise every day, constituting $56 \%$ of this group. In the group who do periodic shift work, there are 12 who exercise 2-3 times per week - just half of the total, 24. This shows that an exercise frequency of 2-3 times a week is the most common for regular commuters and periodic shift workers.

Table 1. Exercise frequency * Working hours Cross Tabulation

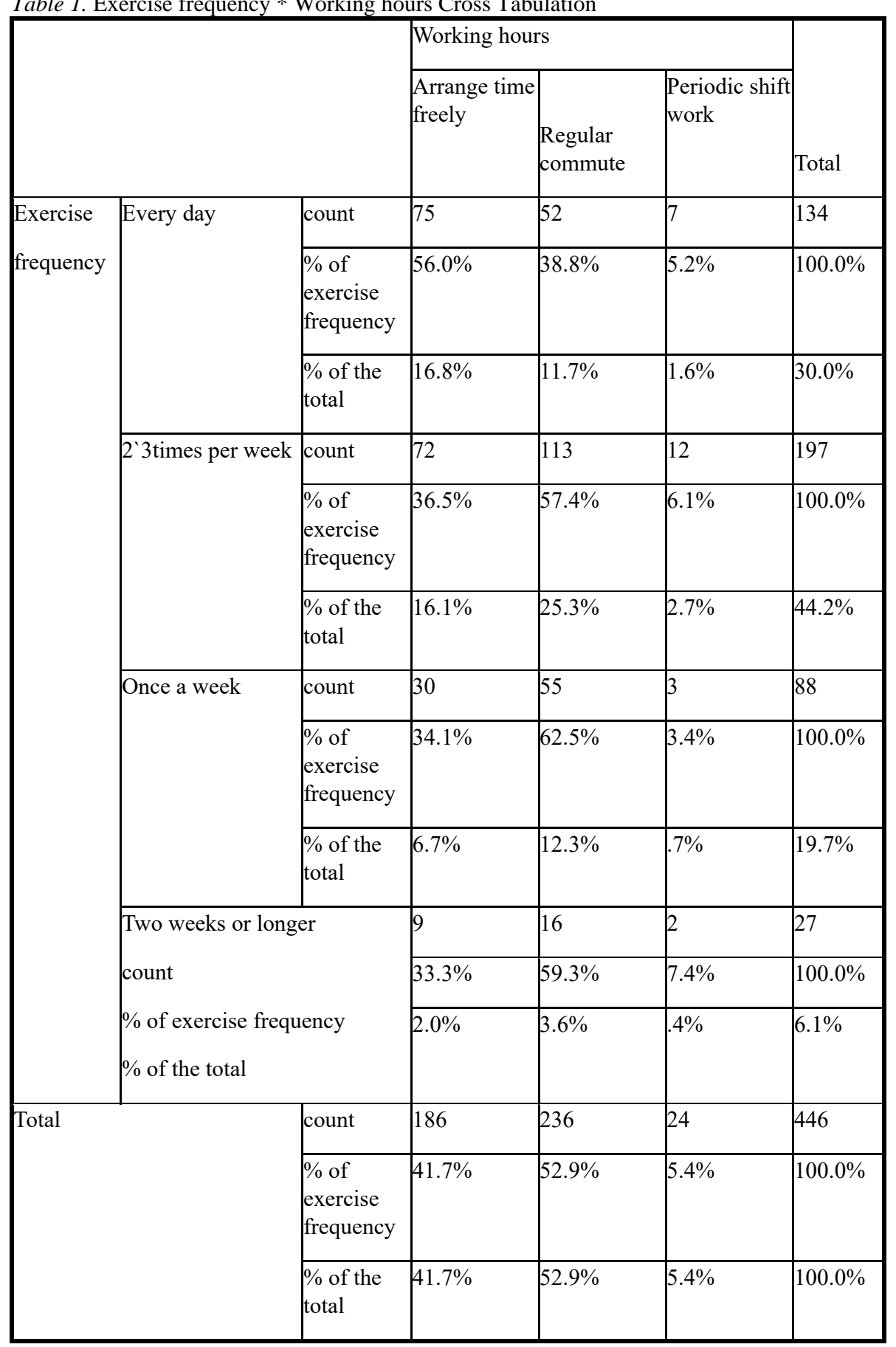




\subsubsection{The choice of individual sports mode of sports group}

The most popular individual exercises were running and walking, which made up $49 \%$ of the total, followed by cycling with $17.9 \%$. Gymnastics, tai chi, qigong, yoga, and eight sections brocade accounted for only $10.1 \%$ of the individual sports population (Table 2).

Table 2. Individual Sports

\begin{tabular}{|c|c|c|c|}
\hline \multicolumn{2}{|c|}{ Types of sports } & Frequency & Proportion (\%) \\
\hline \multirow{3}{*}{ Valid } & Gymnastics, Tai Chi, Qigong & 64 & 14.3 \\
\cline { 2 - 4 } & Yoga or Eight sections brocade & 45 & 10.1 \\
\cline { 2 - 4 } & Cycling & 80 & 17.9 \\
\cline { 2 - 4 } & Running or walking & 219 & 49.0 \\
\cline { 2 - 4 } & Other sports & 39 & 8.7 \\
\cline { 2 - 4 } & Total & 447 & 100.0 \\
\hline Deficiency & Total & 78 & \\
\hline
\end{tabular}

The most frequently chosen team sports were badminton, table tennis, and tennis, accounting for $29.5 \%$ of the total. Secondly, football, basketball, volleyball and other ball games accounted for $21.5 \%$. The percentages for other types of exercise, which together accounted for 18.6 percent of the total, were not included in the questionnaire (Table 3 ).

Table 3. Team Sports

\begin{tabular}{|c|c|c|c|}
\hline \multicolumn{2}{|c|}{ Types of sports } & Frequency & Proportion (\%) \\
\hline \multirow{7}{*}{ Valid } & Square dance & 57 & 12.8 \\
\cline { 2 - 4 } & $\begin{array}{c}\text { Football, basketball, volleyball } \\
\text { and others }\end{array}$ & 96 & 21.5 \\
\cline { 2 - 4 } & Badminton, table tennis, tennis & 132 & 29.5 \\
\cline { 2 - 4 } & Chess, cards & 44 & 9.8 \\
\cline { 2 - 4 } & Hiking, running & 35 & 7.8 \\
\cline { 2 - 4 } & Other sports & 83 & 18.6 \\
\hline Total & 447 & 100.0 \\
\hline Deficiency & Total & 525 & \\
\hline & & & \\
\hline
\end{tabular}

\subsubsection{Health status and exercise habits}

The data shows that $36 \%$ of the respondents who were in poor health did not exercise regularly. $89.6 \%$ of people who were in good health made a habit 
of regular exercise. By the Spearman Rank Correlation analysis, there was a correlation between health status and regular exercise (Table 4).

Table 4. Cross Coefficient of Regular Exercise Habits and Health Status

\begin{tabular}{|l|c|c|c|c|}
\hline \multicolumn{2}{|c|}{} & $\begin{array}{c}\text { Health } \\
\text { status }\end{array}$ & \multicolumn{1}{c|}{$\begin{array}{c}\text { Regular } \\
\text { exercise habits }\end{array}$} \\
\hline \multirow{2}{*}{ Spearman rho } & \multirow{2}{*}{ Health status } & Cross Coefficient & 1.000 & $.182^{* *}$ \\
\cline { 3 - 5 } & & Sig. (two-tailed) & $\cdot$ & .000 \\
\cline { 3 - 5 } & & $\mathrm{N}$ & 525 & 525 \\
\hline
\end{tabular}

**. When the confidence level (two-tailed) was 0.01 , the correlation was significant.

\subsubsection{Analysis of the correlation between gender and exercise preference}

Table 5. Cross Coefficient of Gender and Individual Sports

\begin{tabular}{|c|c|c|c|c|}
\hline \multicolumn{2}{|l|}{} & Gender & $\begin{array}{c}\text { Individual } \\
\text { Sports }\end{array}$ \\
\hline \multirow{2}{*}{ Spearman rho } & \multirow{2}{*}{ Gender } & Cross Coefficient & 1.000 & $-.202^{* *}$ \\
\cline { 3 - 5 } & Sig.(two-tailed) & $\cdot$ & .000 \\
\cline { 3 - 5 } & $\mathrm{N}$ & 525 & 447 \\
\hline
\end{tabular}

**. When the confidence level (two-tailed) was 0.01 , the correlation was significant.

The Spearman Rank Correlation analysis showed that there was a correlation between gender and individual sports types (Table 5). Regarding individual sports options, the percentage of women who chose yoga or eight sections brocade exercise was up to $82.2 \%$, while the percentage of men who chose cycling was up to $68.8 \%$. There was no significant gender difference in other individual sports. In terms of gender and team sports, men preferred ball activities, such as football and basketball, and women tended to prefer square dancing. There were few differences between men and women for other team sports (Figure 3). 


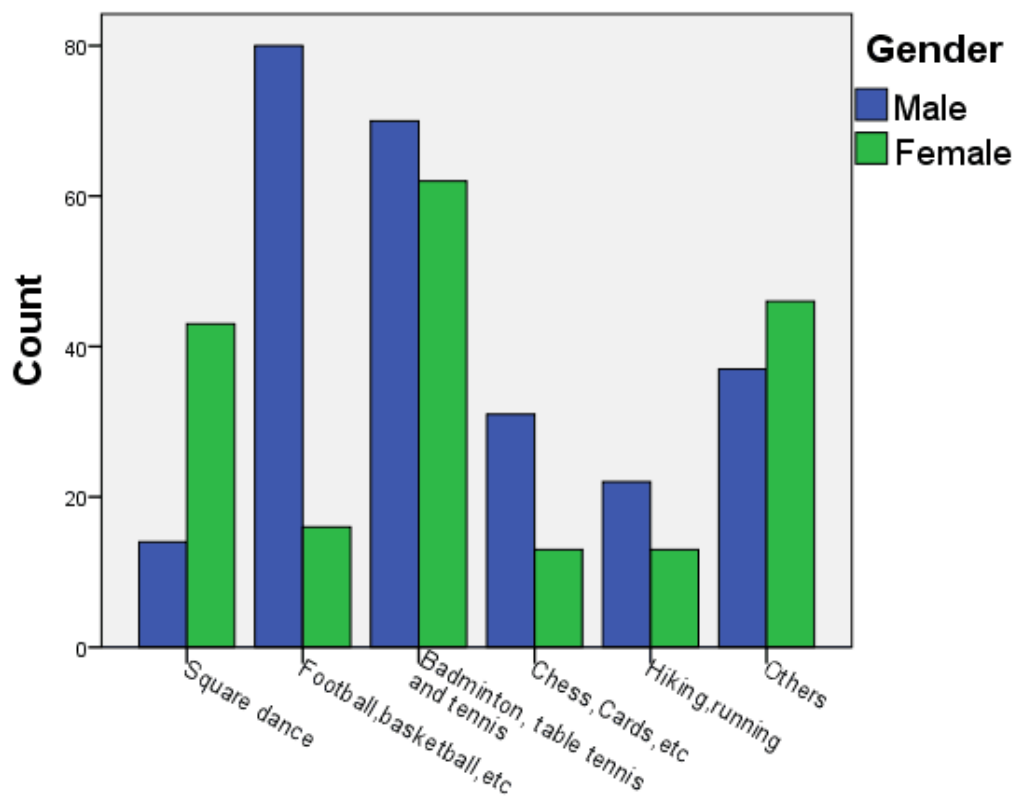

Team sports patterns

Figure 3. Team sports patterns and gender

\subsection{The preference of spaces for sports groups}

\subsubsection{Individual sports and their places}

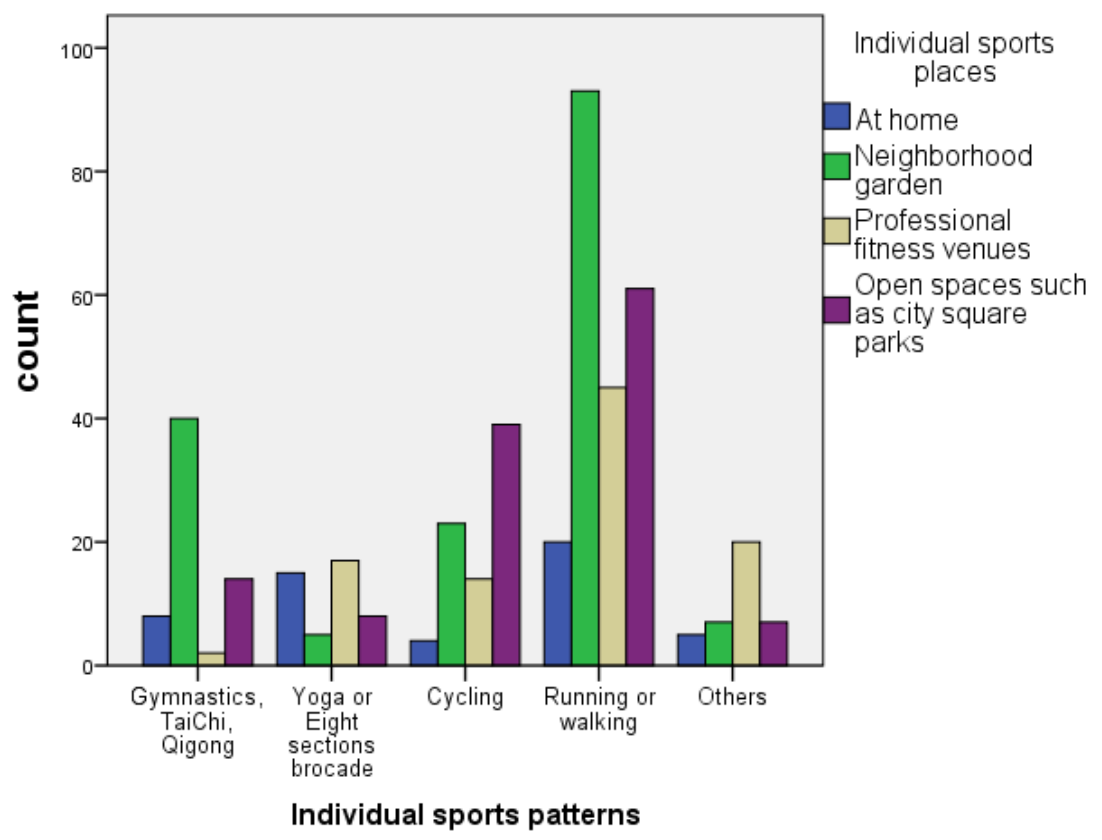

Figure 4. Cross tabulation of individual sports patterns and individual sports places

As can be seen from Figure 4, the most popular exercise type was running or walking, and the favorite places to exercise were neighborhood gardens and public open spaces like urban squares or parks. Home space was the least popular option, revealing that inhabitants preferred to go out and exercise in open spaces, rather than doing fitness sports at home. 


\subsubsection{Team sports and their places}

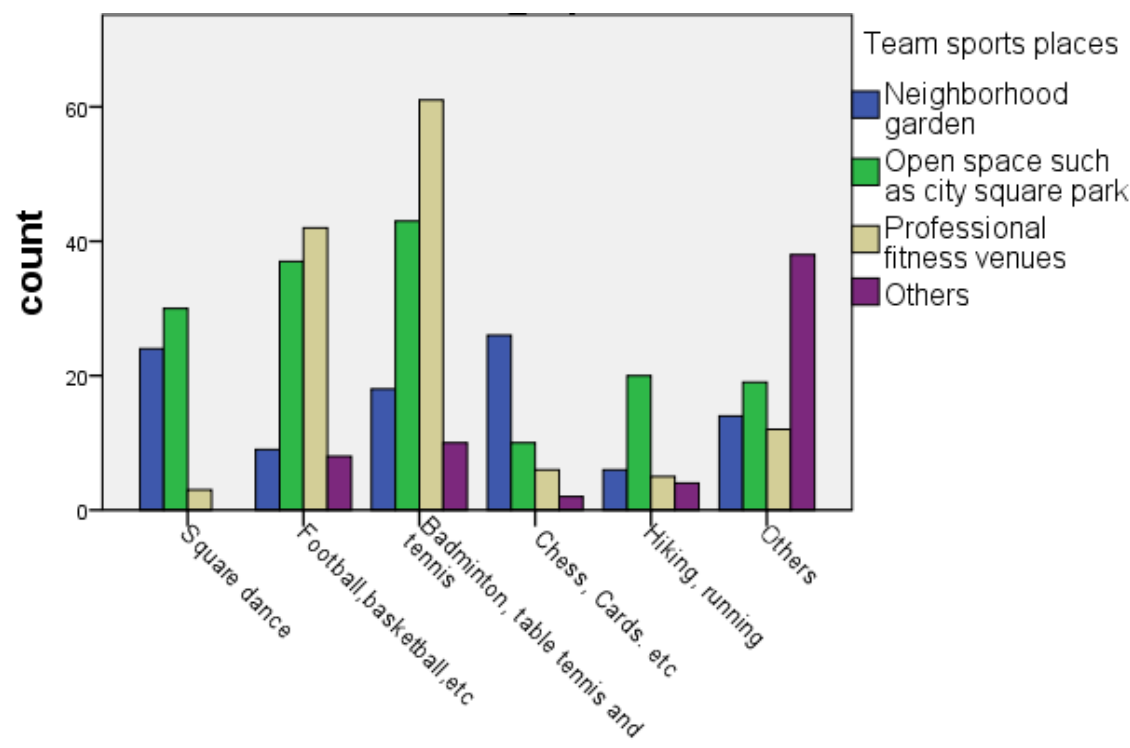

Team sports patterns

Figure 5. Cross tabulation of team sports patterns \& team sports places

Figure 5 showed that the more popular forms of team sports among the respondents were badminton, table tennis, and tennis, followed by football, basketball, and volleyball. The places where inhabitants were most likely to go for team sports were professional fitness venues and open spaces, such as urban squares or parks.

\subsubsection{Privacy for individual sports}

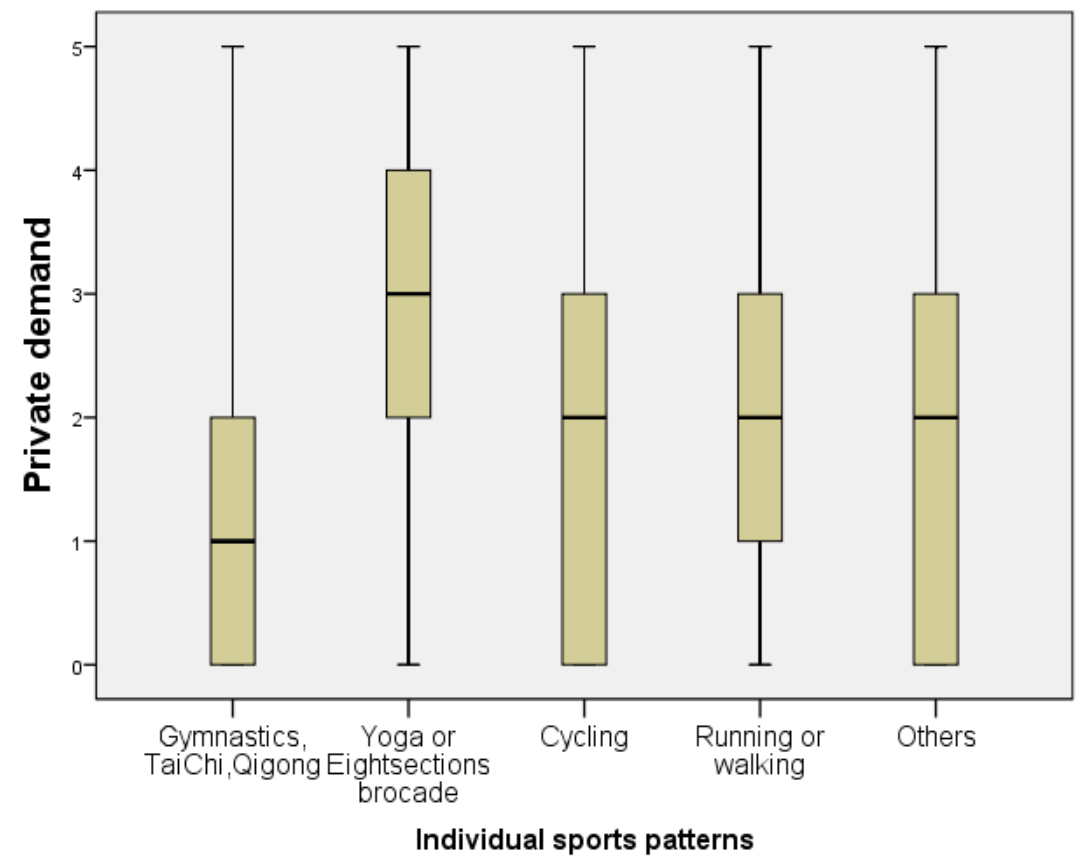

Figure 6. Privacy for individual sports $(0=$ "No requirement" $1=$ "Very low privacy" $2=$ "Low privacy" 3 = "General privacy" 4 = "High privacy" 5 = "Very high privacy") 
It can be seen from Figure 6 that the individual sports that required the highest privacy were yoga and eight-section brocade, while those requiring the lowest privacy were tai chi or qigong.

\subsubsection{Privacy for team sports}

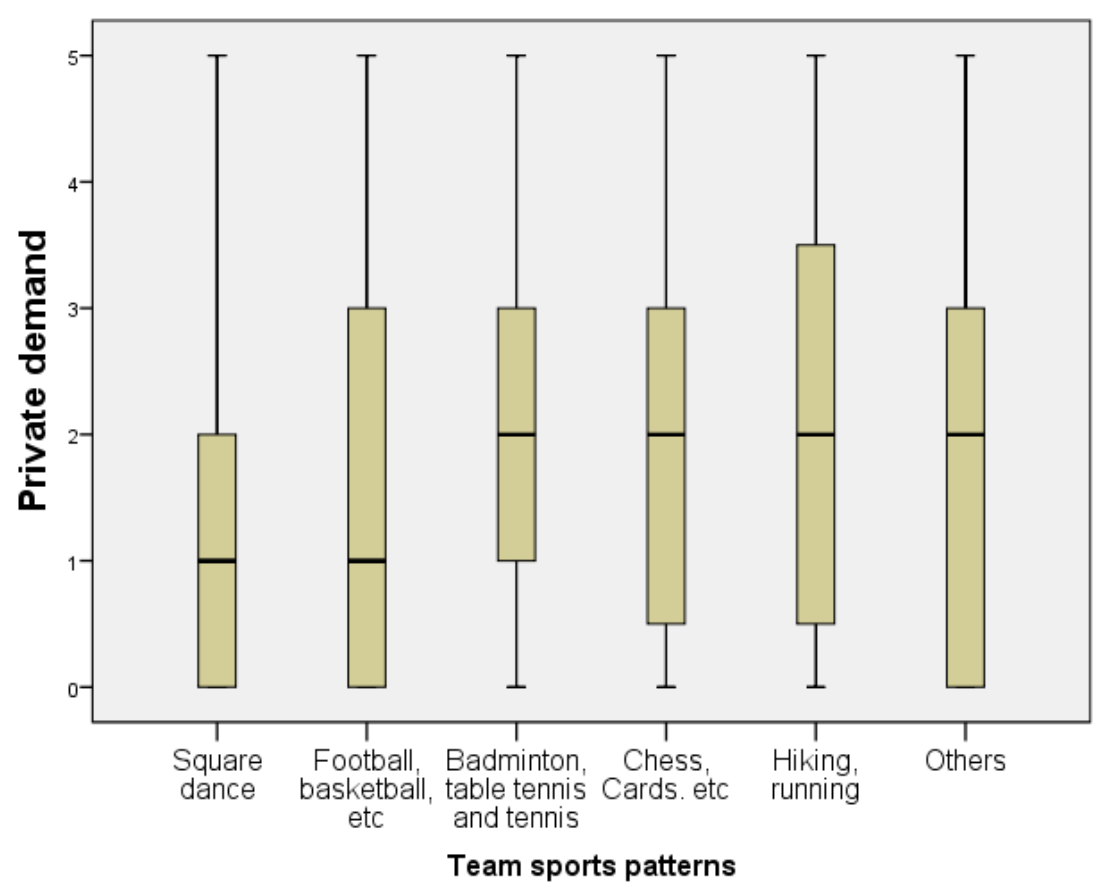

Figure 7. Privacy for team sports $(0=$ "No requirement" $1=$ "Very low demand" 2 = "Low demand" 3 = "General requirements" 4 = "High demand" 5 = "Very high demand")

It can be seen from Figure 7 that there were no significant differences between the different team sports in relation to privacy. Hiking and running required a little more privacy than the other types, possibly owing to the fact that team hiking and running are engaged in on a more professional basis. Square dancing needed lower privacy than any other group activity.

\subsection{The satisfaction of sports places}

\subsubsection{Overall satisfaction statistics}

The mean satisfaction was 0.66 , which showed that respondents were generally satisfied. $(-2=$ "very dissatisfied" - $1=$ "not satisfied" $0=$ "general" 1 = "satisfied" 2 = "very satisfied").

From the cross tabulation between individual sports places and overall satisfaction, the respondents were most satisfied with places where they did individual activities; the rate of satisfaction (satisfied and very satisfied) was $60.6 \%$ ( $42.2 \%$ and $18.4 \%$ respectively).

\subsubsection{The satisfaction of individual sports places}

Regarding the specific choice of exercise location, $11.7 \%$ chose home and the corresponding satisfaction rate was $63.8 \%$. The proportion of the people who chose their neighborhood gardens as their exercise location was $37.8 \%$, and the corresponding satisfaction rate was $63.4 \%$. The proportion of those 
choosing professional fitness venues was $22.0 \%$, and the corresponding satisfaction rate was $55.1 \%$. The proportion choosing public open spaces like urban squares or parks, accounted for $28.5 \%$, and their satisfaction rate was $59 \%$. It is clear that the most satisfying places for individual exercise were homes and neighborhood gardens.

\subsubsection{Analysis of the satisfaction of team sports places}

Regarding the choice of location for team sports, $21.6 \%$ chose neighborhood gardens and the corresponding satisfaction rate was $71.9 \%$. The proportion of people who chose open spaces, such as urban squares or parks was $35.7 \%$, and the corresponding rate was $64.8 \%$. The selection of professional fitness venues accounted for $29 \%$, and the corresponding satisfaction rate was $49.6 \%$. The other options made up $13.7 \%$, where the corresponding satisfaction was $55.7 \%$. The spaces with the highest satisfaction for team activities was neighborhood gardens, followed by public open spaces.

\subsubsection{The ranking statistics of the factors that affect satisfaction}

Table 6. Descriptive statistics of the factors that affect satisfaction

\begin{tabular}{|c|c|c|c|c|c|c|c|}
\hline & & Accessibility & $\begin{array}{l}\text { Good air } \\
\text { quality and } \\
\text { tidy } \\
\text { environment }\end{array}$ & Low cost & $\begin{array}{l}\text { Quality of } \\
\text { facilities }\end{array}$ & $\begin{array}{l}\text { Perfect and } \\
\text { friendly } \\
\text { management }\end{array}$ & $\begin{array}{l}\text { Unaffected } \\
\text { by the } \\
\text { weather }\end{array}$ \\
\hline \multirow[t]{2}{*}{$\mathrm{N}$} & Valid & 426 & 427 & 422 & 425 & 421 & 421 \\
\hline & Missing & 99 & 98 & 103 & 100 & 104 & 104 \\
\hline Mean & & 2.49 & 2.81 & 3.51 & 3.52 & 4.17 & 4.45 \\
\hline Median & & 2.00 & 2.00 & 3.00 & 4.00 & 5.00 & 5.00 \\
\hline Mode & & 1 & 1 & 3 & 4 & 5 & 6 \\
\hline
\end{tabular}

Table 6 shows the factors that influence satisfaction, from strong to weak, ordered by the mean, from smallest to largest: 1) accessibility, 2) good air quality and tidy environment, 3) low cost, 4) quality of the facilities, 5) perfect and friendly management, 6 ) unaffected by the weather.

\subsection{Recommendations on the improvement of community sports places}

The last question of the survey was an open request for recommendations for the improvement of community sports places. The respondents were able to express their ideas to the investigators. From the 525 valid subjects, 190 answers were received. There were a high number of similar answers, given here from most to least frequent: 1) increase the types and quantities of sports facilities (including the number and size of venues) (119); 2) strengthen the management of sports venues (44);3) reduce the impact of sports venues on the residential environment(12); 4) lower the venue fees (10); 5) improve the safety of sports venues $(7) ; 6)$ increase accessibility to sports venues(5). 


\section{CONCLUSION AND DISCUSSION}

Due to the random sampling of this survey and the limited samples, the results may not reflect sports groups in Shenzhen with a high level of completeness and accuracy. The analysis shows that the proportion of the subjects regularly exercising was quite high, accounting for $85.5 \%$. The number may be higher for subjects who were interviewed near sports places, so this does not necessarily reflect the overall proportion of sports groups in Shenzhen. Compared to the recent literature, this study in Shenzhen, China, focuses on the link between different modes of exercise, individual and team, preferred locations, and the influence of gender differences. It is inclusive of multiple sports locations and features of sports groups.

The most popular individual activities are jogging and walking. The most popular team sports activities are ball games, including small ball games (like badminton, table tennis, etc.) and big ball games (like football, basketball, etc.). Regarding the options for sports places, the main choices for individual activities were neighborhood gardens and public open spaces like urban squares or parks; as for team sports places, the main choices were public open spaces and professional fitness venues.

Sport choices are related to gender. Males tend to cycle or run individually and play ball games in teams. Females prefer to do yoga or eight section brocade individually and square dance together. Yoga and eight section brocade require more privacy than other individual activities, and hiking and running as team activities need a little more privacy than other team sports, according to the survey; It is postulated that professional reasons like longterm training and careful preparation may be the reason.

The analysis of the factors influencing the satisfaction of location shows that accessibility, good air quality and tidy environment, and low cost ranked as the top three factors, which showed the importance of accessibility for sports venues. In the recommendations on the improvement of community sports places, the sports groups expected to be able to access more types and quantities of public sports facilities (including the number and size of venues), and they would like better and friendlier management of sports venues.

According to the analysis, if the urban community fitness environment is going to be improved with the goal of a healthier city, the following urban design strategies may be put forward:

- Firstly, focus on the layout of public open spaces in urban planning. Public open spaces are important places for informal sports and social interaction. Multifunctional spaces have great significance on the quality of public life, including providing places for inhabitants' daily fitness activities, so a balanced distribution of urban open spaces will promote the accessibility of sports places.

- Secondly, more must be done to slow the traffic network for walking and cycling. Non-motorized vehicle lanes are the main places for cycling and jogging.

- Thirdly, the types and quantities of sports facilities should be improved; sports facilities in the urban open space should be designed according to the needs of sports groups, and should be friendly, safe and healthy.

- Lastly, it is necessary to construct a management system that involves public participation, which can support the ongoing maintenance, regular post occupancy evaluation, and collection of public opinions and suggestions for improving services that increase inhabitants' satisfaction. 


\section{REFERENCES}

Ciming Health Checkup Management Group Company Limited. (2013). Investigation of Urban Inhabitants'health Status. Daily Sunshine, pp. 2013-2006-2026-B2019.

Giles-Corti, B., \& Donovan, R. J. (2002). "The Relative Influence of Individual, Social and Physical Environment Determinants of Physical Activity". Social Science \& Medicine, 54(12), 1793-1812.

Humpel, N., Owen, N., \& Leslie, E. (2002). "Environmental Factors Associated with Adults' Participation in Physical Activity: A Review". American Journal of Preventive Medicine, 22(3), 188-199.

Jiang, B., Zhang, T., Sullivan, W. C., \& Wu, X. (2015). "A Healthy City: The City Green Landscape on the Influence Mechanism of the Public Health and Important Research Issues". Landscape Architecture Frontiers, 3(1), 24-35.

Jiao, X., Jin, Y., Gunawan, O., \& James, P. (2015). "Modelling Spatial Distribution of Outdoor Recreation Trips of Urban Residents". International Review for Spatial Planning and Sustainable Development, 3(3), 36-49.

Li, M. (2013). "Correlation Analysis of the Relationship between Sports Behavior and Urban Environment". Journal of Nanjing Sport Institute(Social Science), 27(1), 82-85.

Liu, L., Liu, R., \& Peng, C. (2014). "The Influence of Urban Construction Environment on the Inhabitants' Physical Activities and the Measures Taken by the European Union". Journal of Xi'an Physical Education University, (5), 526-530.

Ma, L., Lv, Y., Ren, Q., \& Zhang, X. (2008). "The Selection of Environmental Factors Related to Physical Fitness of Some Inhabitants in Xi'an". Journal of Environment and Health, 25(3), 266.

Sina Health Blog. (2011). "The World Health Organization : Moderate Exercise Can Reduce the Incidence of Cancer". Retrieved from http://health.sina.com.cn/d/2011-0211/075821936682.shtml.

Stevinson, C., Wiltshire, G., \& Hickson, M. (2015). "Facilitating Participation in HealthEnhancing Physical Activity: A Qualitative Study of Parkrun". International Journal of Behavioral Medicine, 22(2), 170-177.

Tsai, S.-Y., Chen, T.-Y., \& Ning, C.-J. (2016). "Elderly People's Social Support and Walking Space by Space-Time Path". International Review for Spatial Planning and Sustainable Development, 4(3), 4-13.

Wei, W., Xia, H., \& Wang, W. (2014). "Exploration on the Plants Configuration of Outdoor Fitness Environment of the City". Sports Culture Guide, (8), 198-201.

Weng, X., He, X., Wang, X., Lin, W., \& Li, D. (2010). "Urban Building Environment Effects of Inhabitants Physical Activity and Health - New Research Field of Sports and Health Promoting". China Sport Science, 30(9), 3-11.

Zhao, H., \& Huang, S. (2016). The Incidence of Gout in Shenzhen Is 3 Times the National Average. Shenzhen Economic Daily. Retrieved from http://szsb.sznews.com/html/201607/18/content_3573016.htm

Zheng, J. (2017). The Patients with Dyslipidemia in Shenzhen Higher Than the National Average. Shenzhen Economic Daily. Retrieved from http://szsb.sznews.com/html/2017 04/14/content 3768424.htm 